\title{
TIME AND TIME AGAIN: GETTING IT RIGHT
}

BERGGREN, William A., Dept. Geology and Geophysics, Woods Hole Oceanographic Institution, Woods Hole, MA 05423, U.S.A.

The passage of time cannot be measured in vacuo. Recognition of the timecontinuum can only be made by reference to physical and/or biotic events in the geohistorical (rock) record. Inasmuch as these events in the rock record must be measurable in some fashion, they must be related to an objective and retrievable reference standard. Thus the "holy trinity" of litho-bio-and chronostratigraphy can serve as the material (concrete) evidence for the totally conceptual geochronologic units which have no objective existence apart from the natural world.

Geochronology is defined here as the conceptual division of continuous time as measured (geochronometry) by the progression in an ordinal series of events. This is best achieved by an approach which integrates four independent data sets: magnetostratigraphy, sea-floor spreading magnetic anomalies, biostratigraphy and isotopic dating. This integrated approach has resulted, until recently, in an ordinal framework capable of measuring the passage of time with greater resolution (precision), though perhaps with less accuracy, than a radiometric approach alone. Recent improvements in the field of isotopic dating-the single crystal laser fusion (SCLF) ${ }^{40} \mathrm{Ar} /{ }^{39} \mathrm{Ar}$ technique - now render possible dates with analytical precision of $<1 \%$ in the early to mid-Cenozoic. The implication for high resolution correlation is clear: until recently biostratigraphy and biochronology have been routinely able to achieve a degree of chronologic resolution considerably higher than that of isotopic dating with its inherently large analytical errors. Laser fusion dating is now capable of providing numerical values for parts of the stratigraphic record with comparable or greater precision than classical biostratigraphy and biochronology. It is clear, now more than ever, that an accurate and precise biostratigraphy is important as we continue to improve upon the geochronologic framework which underlies attempts at high resolution correlation between marginal, platform and deep-sea stratigraphies.

A review of the philosophic and methodologic approach of various Cenozoic geochronologic schemes and their strengths and weaknesses will be presented together with a brief discussion of a new, and as yet unpublished, revision to Cenozoic geochronology. Recent assessment of sea floor anomaly patterns indicate a need to stretch the spacing of the interval between anomalies $3 \mathrm{~A}$ to 5 resulting in an age increase of about $0.5 \mathrm{my}$ for Anomaly 5 from 8.92-10.42Ma (BKVC85) to 9.6-11.0Ma; the revised age estimates are consistent with those of McDougall (1984) based on radioisotopic dating of Icelandic basalts. No other major (age) revisions to Neogene chronology are contemplated. However, discrete adjustments are required in the late Neogene as magnetostratigraphic boundaries and biostratigraphic datum events are (re)correlated to the recently proposed astronomically calibrated orbital time scale of Hilgen and Langereis. In the Paleogene the major change is centered on readjustment of the Eocene which, while retaining its relative duration of $\sim 21 \mathrm{my}$, has younger $(\sim 34 \mathrm{Ma})$ and older $(\sim 54.5 \mathrm{Ma})$ limits, respectively, not unlike some estimates made over 20 years ago. Emphasis on implications for Paleogene geochronology will be stressed with particular reference to events around the Paleocene/Eocene boundary and the integration of correlative NW European and Gulf and Atlantic Coastal Plain stratigraphies in a sequence stratigraphic framework. The continuing efforts being devoted to revising Cenozoic geochronology have as their overiding goal the simple yet scientifically elusive objective of "getting it right". 